\title{
Jackson Cross Cylinder
}

\section{Partha Haradhan Chowdhury ${ }^{1 *}$ and Brinda Haren Shah ${ }^{2}$}

${ }^{1}$ M.Optom, Associate Professor, Principal, Department of Optometry, Shree Satchandi Jankalyan Samiti Netra Prasikshan Sansthan, Pauri, Affiliated to Uttarakhand State Medical Faculty, Dehradun, India

${ }^{2}$ M.Optom, Guest Lecturer, Department of Optometry, Shree Satchandi Jankalyan Samiti Netra Prasikshan Sansthan, Pauri, Affiliated to Uttarakhand State Medical

\section{Short Communication}

Volume 3 Special Issue 2

Received Date: October 06, 2018

Published Date: November 08, 2018

DOI: $10.23880 /$ oajo-16000S2-023

Faculty, Dehradun, India

*Corresponding author: Partha Haradhan Chowdhury, M. Optom, Associate Professor, Principal, Department of Optometry, Shree Satchandi Jankalyan Samiti Netra Prasikshan Sansthan, Pauri, Affiliated to Uttarakhand State Medical Faculty, Dehradun, India, Email: optometrypublish@gmail.com

\section{Abstract}

This paper describes about Jackson Cross Cylinder, its technique and JND technique.

Keywords: Jackson Cross Cylinder; JND technique

\section{Introduction}

Jackson cross cylinder is an instrument by which we can be able to know:

* Axis Refinement

* Power of the cylindrical correction

* Used for near point testing

The procedure of Jackson Cross Cylinder should be followed without fogging. It is a sphero cylinder lens in which plus cylinder is incorporated at the front surface and it is indicated with green sign. Minus cylinder is incorporated at the posterior surface and it is indicated with the red sign [1-3].

So, according to the JCC power, we should know:
A. If, JCC : + / -0.25
i. $+0.25 /-0.50$
ii. $-0.25 /+0.50$

B. If, JCC: $+/-0.50$

i. $0.50 /-1.00$

ii. $-0.50 /+1.00$

C. If, JCC : $+/-0.75$

i. $+0.75 /-1.50$

ii. $-0.75 /+1.50$

D. If, JCC: $+/-1.00$

i. $\quad+1.00 /-2.00$

ii. $-1.00 /+2.00$

E. If, JCC : $+/-1.25$

i. $+1.25 /-2.50$

ii. $-1.25 /+2.50$

\section{Technique}

By the JCC, we can do axis refinement and power of the cylinder. 


\section{Open Access Journal of Ophthalmology}

\section{Axis Refinement}

Here, JCC handle is parallel with the correcting lens axis.

Eg, RE: $-0.50 \mathrm{Dcyl} * 180$

LE: -0.50 Dcyl*180

During, Axis Refinement, JCC handle will be placed parallel to the axis of the correcting lens. It means, in this time automatically, JCC axis will be positioned 45 degree and 135 degree compared to the correcting lens axis.

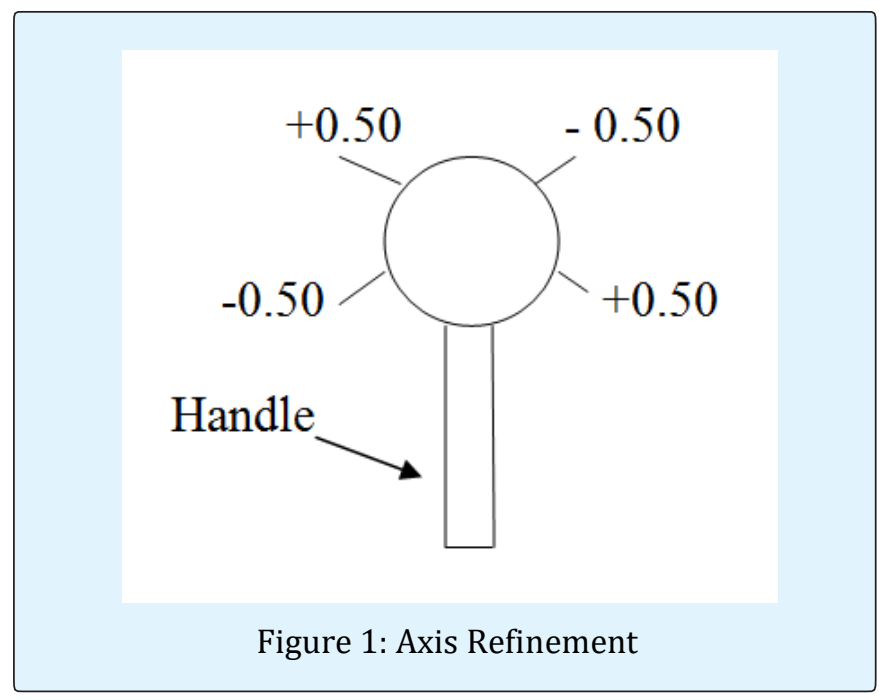

\section{Power of the Cylinder Correction}

JCC axis is parallel with the axis of the correcting lens. $1^{\text {st }}$ time minus axis is parallel and then flip the JCC, plus axis will be parallel.

\section{Just Noticeable Difference}

By this technique, we can be able to know which JCC should be used according to high refractive error.

JND technique with e.g.

\section{Eg. 1}

If patient's visual acuity is $20 / 200$

In this technique, always 10 is divided by 100 , i.e. $10 / 100$

After that, if 200 is divided by 100

So, $200 / 100=+/-2.00 \mathrm{D}$

In this case, +/- 2.00 D JCC is used.

\section{Eg. 2}

If visual acuity of patient is $20 / 400$,

At first, 10 is divided by 100

So, $10 / 100$

After that, 400 will be divided by 100

So, $400 / 100=+/-4.00 \mathrm{D}$

In this case, +/- 4.00 D JCC will be used as per the case.

\section{References}

1. William J Benjamin (2006) Borish's Clinical Refraction. 2 ${ }^{\text {nd }}$ (Edn.).

2. Theodore Grosvenor, Theodore P. Grosvenor (2007) Primary Care Optometry, $5^{\text {th }}$ (Edn.).

3. Duke-Elder S, David Abrams (1978) Duke-Elder's Practice of refraction. 